\title{
Modeling the influence of stromal microenvironment in the selection of ENU-induced BCR-ABL1 mutants by tyrosine kinase inhibitors
}

\author{
Djamel Aggoune ${ }^{1}$, Lucie Tosca ${ }^{2,3,4}$, Nathalie Sorel ${ }^{1,5}$, Marie-Laure Bonnet ${ }^{1}$, Fatima \\ Dkhissi $^{1}$, Gérard Tachdjian ${ }^{2,3,4}$, Annelise Bennaceur-Griscelli ${ }^{2,3,6}$, Jean-Claude \\ Chomel $^{1,5}$ and Ali G Turhan ${ }^{1,2,3,7}$ \\ ${ }^{1}$ INSERM, U935, F-86000 Poitiers, France \\ 2 INSERM, U935, F-94800, Villejuif, France \\ ${ }^{3}$ Université Paris-Sud 11, F-94270 Le Kremlin-Bicêtre, France \\ ${ }^{4}$ Hôpital Antoine Béclère, Service d'Histologie-Embryologie-Cytogénétique, F-92140 Clamart, France \\ ${ }^{5} \mathrm{CHU}$ de Poitiers, Service de Cancérologie Biologique, F-86000 Poitiers, France \\ ${ }^{6}$ Hôpital Paul Brousse, Service d'Hématologie Biologique, F-94800 Villejuif, France \\ ${ }^{7}$ Hôpital Bicêtre, Service d'Hématologie Biologique, F-94270 Le Kremlin Bicêtre, France \\ Correspondence to: Ali G Turhan, email: ali.turhan@bct.aphp.fr \\ Keywords: ENU-mutagenesis, BCR-ABL1, CML, microenvironment, TKI resistance \\ Received: December 21,2013 Accepted: January 20,2014 Published: January 30, 2014
}

This is an open-access article distributed under the terms of the Creative Commons Attribution License, which permits unrestricted use, distribution, and reproduction in any medium, provided the original author and source are credited.

ABSTRACT:

Tyrosine kinase inhibitors (TKIs) have profoundly changed the natural history of chronic myeloid leukemia (CML). However, acquired resistance to imatinib, dasatinib or nilotinib ( $1^{\text {st }}$ and $2^{\text {nd }}$ generation TKIs), due in part to BCR-ABL1 kinase mutations, has been largely described. These drugs are ineffective on the T315I gatekeeper substitution, which remains sensitive to $3^{\text {rd }}$ generation TKI ponatinib. It has recently been suggested that the hematopoietic niche could protect leukemic cells from targeted therapy. In order to investigate the role of a stromal niche in mutation-related resistance, we developed a niche-based cell mutagenesis assay. For this purpose, ENU ( $\mathrm{N}$-ethyl-N-nitrosourea)-exposed UT-7 cells expressing nonmutated or T315I-mutated BCR-ABL1 were cultured with or without murine MS-5 stromal cells and in the presence of imatinib, dasatinib, nilotinib, or ponatinib. In the assays relative to $1^{\text {st }}$ and $2^{\text {nd }}$ generation TKIs, which were performed on non-mutated BCR-ABL1 cells, our data highlighted the increasing efficacy of the latter, but did not reveal any substantial effect of the niche. In ponatinib assays performed on both non-mutated and T315I-mutated BCR-ABL1 cells, an increased number of resistant clones were observed in the presence of MS-5. Present data suggested that T315I mutants need either compound mutations (e.g. E255K/T315I) or a stromal niche to escape from ponatinib. Using array-comparative genomic hybridization experiments, we found an increased number of variations (involving some recurrent chromosome regions) in clones cultured on MS-5 feeder. Overall, our study suggests that the hematopoietic niche could play a crucial role in conferring resistance to ponatinib, by providing survival signals and favoring genetic instability.

\section{INTRODUCTION}

Chronic myeloid leukemia (CML) is a paradigm of leukemogenesis initiated by the appearance of the Philadelphia (Ph1) chromosome in a primitive hematopoietic stem cell (HSC) [1]. The $B C R-A B L 1$ fusion gene, which is the counterpart of the Ph1 chromosome, gives rise to the $\mathrm{p} 210^{B C R-A B L I}$ protein characterized by 
deregulated tyrosine kinase activity. It is thought to be responsible for the phenotypic features of the disease, including genetic instability [2]. The ability to target this tyrosine kinase protein by the use of small inhibitors is challenging since BCR-ABL1 activates a plethora of signaling pathways [3]. In this context, imatinib, which showed selective inhibitory activity with regard to BCRABL1, was the first TKI (tyrosine kinase inhibitor) developed and tested successfully in patients to become the standard front-line treatment of chronic phase CML $[4,5]$. However, up to $20-30 \%$ of patients develop resistance towards imatinib. This phenomenon can be either oncogene-dependent (e.g. BCR-ABL1 amplification or mutations), or -independent (e.g. activation of SRC kinase families) [6].

Point mutations occurring within the BCR-ABL1 kinase domain (KD) have become the most widely known mechanism of imatinib resistance. Up until now, over 100 mutations affecting 70 amino acids have been described [7]. In order to efficiently target these mutants, secondgeneration TKIs have been developed. Nilotinib, of which the design was based on imatinib, binds to BCR-ABL1 with better efficacy [8]. Dasatinib, which was developed first as a SRC inhibitor, can bind the BCR-ABL1 KD regardless of the activation loop conformation [9]. Just like nilotinib, it is more potent than imatinib but is less selective than either. Second-generation TKIs are currently used in clinical practice and are efficient on most of the mutants, with the exception of the threonine-isoleucine substitution at position 315 (T315I) [10]. More recently, ponatinib, considered as a pan-BCR-ABL1 inhibitor, was shown to be active against T315I mutants [11].

It is now well established that primitive HSCs are refractory to all TKIs used in clinical practice [12-14]. This resistance to TKIs can be acquired through different mechanisms, but a close relation between leukemic stem cells (LSCs) and the bone marrow microenvironment could play a particularly important role $[15,16]$. The stem cell niche can provide survival and/or quiescence signals to LSCs and favor the persistence of a pool of residual leukemic clones comprising mutants.

The objective of the present work was to apprehend the potential influence of the microenvironment in the emergence of BCR-ABL1 KD mutants in the presence of TKI. For that purpose, we developed a niche-based cell mutagenesis assay using UT-7 cells expressing native or T315I mutated BCR-ABL1 (as CML models) and the murine stromal cell line MS-5 (as a niche model). This cell line creates a surrogate microenvironmental niche that can promote the expansion or differentiation of human HSCs in vitro. Using this screening protocol, four TKIs (imatinib, nilotinib, dasatinib and ponatinib) were tested. TKI-resistant UT-7 clones, appearing in the presence or in the absence of the niche, were analyzed for BCR-ABL1kinase mutations, and some of them were further analyzed by array-comparative genomic hybridization (array-CGH).
The present strategy highlighted a potential role of the stromal niche in the acquired resistance of T315I mutants towards ponatinib.

\section{RESULTS}

\section{Mutagenesis assay in UT-7 cells and TKI selection}

Our assay was based on human UT-7 cell lines (expressing non-mutated or T315I-mutated BCRABL1), mutagenized with ENU (N-ethyl-N-nitrosourea) and cultured with or without murine MS-5 stromal cells in the presence of imatinib, dasatinib, nilotinib, or ponatinib (Supplementary Fig. S1). UT-7 cell lines were characterized with regard to BCR-ABL1 expression by western blots. As expected, the BCR-ABL1 oncoprotein was detected in UT-7-11 and UT-7-315, but not in parental UT-7 cell line from which they were derived (Supplementary Fig. S2A). In addition, mutation screening of the BCR-ABL1 KD domain by DGGE (denaturing gradient gel electrophoresis) confirmed the presence of the gatekeeper mutation in UT-7-315 and the absence of any mutation in UT-7-11 or in parental UT-7 cell line (Supplementary Fig. S2B).

To establish the optimal ENU concentration, we tested four different doses $(25,50,75$ and $100 \mu \mathrm{g} / \mathrm{ml})$ and determined cell viability using a trypan blue exclusion assay after $24 \mathrm{~h}$ of culture. With mortality exceeding 50 $60 \%$, concentrations higher than $50 \mu \mathrm{g} / \mathrm{ml}$ appeared to be very toxic for UT-7 cells, whereas an acceptable toxicity was achieved with $50 \mu \mathrm{g} / \mathrm{ml}(20 \%)$. A pilot study, with 24 clones, was then performed to verify the ability of ENU to induce mutagenesis at this concentration. All the clones tested were mutated and harbored at least one mutation in the BCR-ABL1 KD domain. Because $50 \mu \mathrm{g} / \mathrm{ml}$ ENU was

\begin{tabular}{|c|c|c|c|c|}
\hline $\begin{array}{l}\text { Table } \\
\text { clone } \\
\text { withe } \\
96-w\end{array}$ & $\begin{array}{l}1: \text { Num } \\
\text { s recover } \\
\text { ut MS-5 } \\
\text { ell plates. }\end{array}$ & $\begin{array}{l}\text { ber and pe } \\
\text { ed from } E \\
\text { feeder and }\end{array}$ & $\begin{array}{l}\text { rcentage of } T \\
\text { NU-treated c } \\
\text { after 5-6 wee }\end{array}$ & $\begin{array}{l}\text { KI resistant } \\
\text { lls with or } \\
\text { culture in }\end{array}$ \\
\hline Exp. & TKI & $\begin{array}{c}\text { UT-7 } \\
\text { cell line }\end{array}$ & $\begin{array}{c}\text { Without } \\
\text { MS-5 feeder }\end{array}$ & $\begin{array}{l}\text { With } \\
\text { MS-5 } \\
\text { feeder }\end{array}$ \\
\hline 1 & imatinib & UT-7-11 & $54(56 \%)$ & $51(53 \%)$ \\
\hline 2 & nilotinib & UT-7-11 & $31(32,3 \%)$ & $0(0 \%)^{*}$ \\
\hline 3 & dasatinib & UT-7-11 & $12(12.5 \%)$ & $11(11.5 \%)$ \\
\hline $4 \mathrm{a}$ & ponatinib & UT-7-315 & $65(68 \%)$ & $96(100 \%)$ \\
\hline $4 b$ & ponatinib & UT-7-315 & $68(71 \%)$ & $96(100 \%)$ \\
\hline 5 & ponatinib & UT-7-11 & $0(0 \%)$ & $96(100 \%)$ \\
\hline $\begin{array}{l}* \text { No } \\
\text { feeder } \\
\text { nilotin }\end{array}$ & growth obs & erved (viable & T-7-11 located & $\begin{array}{l}\text { ithin the MS-5 } \\
\text { the presence of } \\
\text { days of culture. }\end{array}$ \\
\hline
\end{tabular}




\begin{tabular}{|c|c|c|c|c|c|c|c|c|}
\hline \multirow{2}{*}{ Exp. } & \multirow{2}{*}{ TKI } & \multirow{2}{*}{$\begin{array}{l}\text { UT-7 } \\
\text { cell line }\end{array}$} & \multirow{2}{*}{ MS-5 feeder } & \multicolumn{2}{|c|}{$\begin{array}{l}\text { Clones tested for } \\
\text { mutation }\end{array}$} & \multicolumn{3}{|c|}{ Results of mutation analysis } \\
\hline & & & & Number & Available** & $\begin{array}{c}\text { No } \\
\text { mutation }\end{array}$ & $\begin{array}{c}\text { one } \\
\text { mutation }\end{array}$ & $\begin{array}{c}\text { two } \\
\text { mutations }\end{array}$ \\
\hline \multirow{2}{*}{1} & \multirow{2}{*}{ imatinib } & \multirow{2}{*}{ UT-7-11 } & - & 24 & 22 & 2 & 20 & 0 \\
\hline & & & + & 24 & 23 & 0 & 23 & 0 \\
\hline \multirow{2}{*}{2} & \multirow{2}{*}{ nilotinib } & \multirow{2}{*}{ UT-7-11 } & - & 24 & 24 & 11 & 12 & 1 \\
\hline & & & + & $24 *$ & 24 & 13 & 11 & 0 \\
\hline \multirow{2}{*}{3} & \multirow{2}{*}{ dasatinib } & \multirow{2}{*}{ UT-7-11 } & - & 12 & 12 & 1 & 11 & 0 \\
\hline & & & + & 11 & 11 & 1 & 10 & 0 \\
\hline \multirow{2}{*}{4} & \multirow{2}{*}{ ponatinib } & \multirow{2}{*}{ UT-7-315 } & - & 48 & 47 & 0 & $10 * * *$ & $37 * * * *$ \\
\hline & & & + & 48 & 46 & 0 & $34 * * *$ & $12 * * * *$ \\
\hline \multirow{2}{*}{5} & \multirow{2}{*}{ ponatinib } & \multirow{2}{*}{ UT-7-11 } & - & 0 & 0 & 0 & 0 & 0 \\
\hline & & & + & 24 & 24 & 0 & $22 * * *$ & $2 * * * *$ \\
\hline
\end{tabular}

shown to be efficient without high toxicity, this dose was subsequently used in culture experiments.

In order to determine the concentration of each TKI used in the mutagenesis assay, UT-7 parental cell line and BCR-ABL1-expressing counterparts were tested for cell viability after 72 hours of exposure using trypan blue exclusion assay. For each TKI, a range of concentrations was tested on all UT-7 cell lines, and the concentration corresponding to the beginning of the plateau was retained as effective (Supplementary Table S1). In the presence of TKIs, due to the lack of the BCR-ABL1 oncogene, UT-7 parental cells displayed minimal cell death. All 4 TKIs appeared active on UT-7-11 cells expressing non-mutated BCR-ABL1 since elevated cell death percentage was observed in all conditions. As expected, only ponatinib caused cell death on $86 \%$ of T315I mutated BCR-ABL1 expressing cells (UT-7-315). For optimal selection pressure, the working TKI concentrations chosen were higher than the effective dose; i.e. $2 \mu \mathrm{M}$ for imatinib, $75 \mathrm{nM}$ for nilotinib, $10 \mathrm{nM}$ for dasatinib and $30 \mathrm{nM}$ for ponatinib.

\section{Outgrowth of TKI-resistant clones: Effect of the MS-5 niche}

The first objective of the present screening was to evaluate the potential role of MS-5 feeder cells on the emergence of TKI-resistant UT-7 clones after ENU treatment. With that in mind, for each TKI (imatinib, nilotinib, dasatinib or ponatinib), UT-7-11 mutagenized cells were cultured in two 96-well plates with or without MS-5 feeder cells. To mimic the clinical condition in which a patient carrying the gatekeeper mutation is treated with ponatinib, the ENU-mutagenesis test was performed on UT-7-315 cells. During this assay, experiments were conducted in duplicate ( 2 plates with MS-5 and 2 plates without). UT-7 cell growth was evaluated by microscopic inspection of each well twice a week for 5-6 weeks. A well was considered as positive when cell growth was observed in the presence of the drug. In the absence of viable UT-7 cells, the well was considered as negative. Positive and negative wells were enumerated in all plates in order to determine, after TKI selection, the number and percentage of TKI-resistant clones with or without MS-5 feeder.

Table 1 summarizes the results of these experiments. The number of imatinib-resistant UT-7 clones was similar when the mutagenized cells were grown in the absence $(56 \%)$ or in the presence $(53 \%)$ of MS-5. Similarly, dasatinib selection yielded similar percentages of UT-7 resistant clones in the absence $(12.5 \%)$ or in the presence $(11.5 \%)$ of the stromal niche. Using the same experimental conditions and nilotinib, no outgrowth of UT-7-11 resistant clones with MS-5 feeder was observed. Nevertheless, viable cells located within the MS-5 feeder were detected by meticulous microscopic inspection. To confirm the presence of these UT-7-11 clones, 24 wells were randomly selected and replated in methylcellulose, in the presence of $75 \mathrm{nM}$ nilotinib. After culture for 14 days, hematopoietic colonies were recovered in all cases, thereby confirming the presence of nilotinib-resistant UT7-11 cells. Importantly, this phenomenon was not observed in the screenings involving other TKIs.

Ponatinib experiments were first performed using UT-7-315 cells, which are considered as sensitive to this drug. In the experimental conditions defined above, $68 \%$ of the wells were resistant to ponatinib in the absence of MS-5 feeder, whereas all wells appeared resistant to this drug in its presence (Table 1, experiment 4a). These results were reproduced in a second independent experiment (Table 1, experiment $4 \mathrm{~b}$ ). These data clearly 
suggested that the stromal microenvironment could play a role in resistance to ponatinib, whereas it does not seem to confer an additional resistance to imatinib or dasatinib. In an attempt to differentiate the respective roles of UT7-315 mutants and MS-5 cell line in ponatinib resistance, mutagenesis assays were also performed starting with UT-7-11 cells (wild-type BCR-ABL1). In the absence of the feeder layer, no growth was observed, whereas all wells displayed outgrowth when cocultured with MS-5, suggesting a specific involvement of the microenvironment in ponatinib resistance (Table 1, experiment 5).

\section{BCR-ABL1 KD mutations and TKI resistance generated by ENU mutagenesis}

The niche-based cell mutagenesis assay performed on UT-7-11 cells or UT-7-315 cells allowed detection of
TKI-resistant clones. A series of 24 resistant clones was then randomly selected and tested for BCR-ABL1 KD mutations. Since very few wells appeared positive for dasatinib (12 without MS-5 and 11 with MS-5), all clones were tested. For ponatinib and UT-7-315 cells, 24 clones were picked from each experiment. Concerning nilotinib with MS-5 condition, mutation screening was carried out on hematopoietic colonies after methylcellulose culture. Most of the clones from all experiments were expanded and subsequently analyzed for KD mutations (233/239). As a first step, mutation screening was performed using both DGGE protocol and direct sequencing (Supplementary Fig. S3). Since DGGE did not detect any minority mutant cell populations, direct sequencing was subsequently used alone for all the samples.

In UT-7-11 screening with imatinib and $2^{\text {nd }}$ generation TKIs, only one mutation was found in more than $90 \%$ of the clones tested with the exception of the

A) Imatinib $2 \mu \mathrm{M} / \mathrm{UT}-7-11$

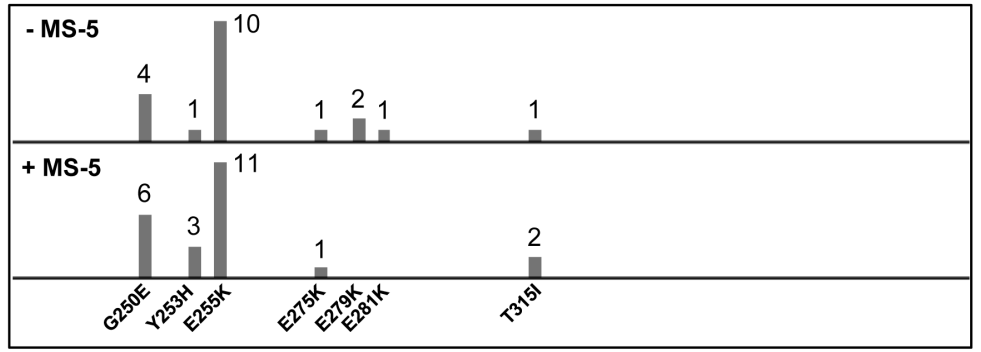

B) Nilotinib 75nM/ UT-7-11

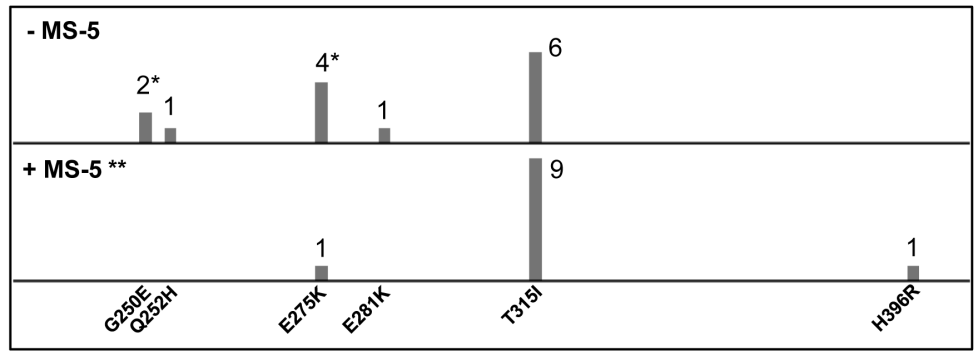

\section{C) Dasatinib $10 \mathrm{nM} / \mathrm{UT}-7-11$}

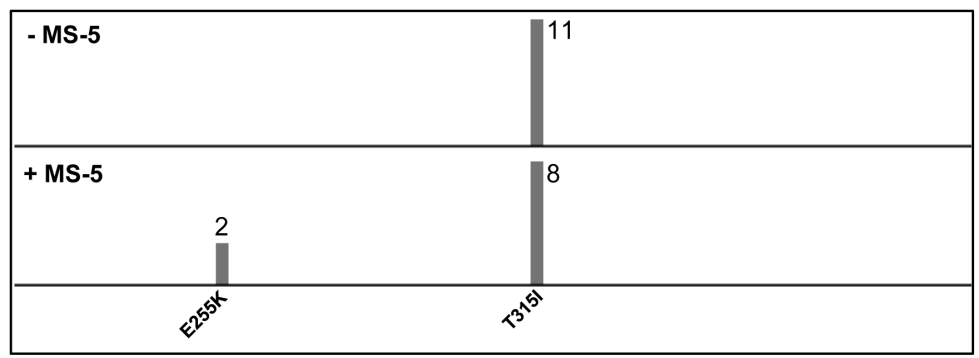

Figure 1: ENU mutagenized resistant clones from UT-7-11 cells treated with $1^{\text {st }}$ and $2^{\text {nd }}$ generation TKIs (imatinib, nilotinib and dasatinib) with or without the stromal cell line MS-5. (A) Clones resistant to imatinib at a concentration of $2 \mu \mathrm{M}$. (B) Clones resistant to nilotinib at a concentration of $75 \mathrm{nM}$. (C) Clones resistant to dasatinib at a concentration of $10 \mathrm{nM}$. Each bar represents the number of clones of the indicated $\mathrm{KD}$ mutation. * Only one clone carried a compound mutation $(\mathrm{G} 250 \mathrm{E}+\mathrm{E} 275 \mathrm{~K})$ and was counted in both bars in this condition. ** No outgrowth was observed in this condition; 24 clones were tested after 14 days of culture in methylcellulose. 
nilotinib selection (Table 2, exp. 1-3). A single clone with a compound mutation was observed in the nilotinib/ without MS-5 screening. In addition, no difference was observed according to whether or not the MS-5 feeder was present (imatinib, nilotinib and dasatinib selection). As expected, all mutagenized UT-7-315 cells harbored the T315I mutation. A $2^{\text {nd }}$ mutation was detected in $79 \%$ of the cases when MS-5 cells were absent and in only $26 \%$ when they were present (Table 2, exp. 4). These data suggest that the stromal niche plays a potential role in ponatinib resistance. The constant detection of T315I mutation in the UT-7-11/ponatinib/with MS-5 screening strengthened this hypothesis (Table 2, exp. 5).

BCR-ABL1-Kinase Mutation profiles in the absence or in the presence of MS-5 niche

For $1^{\text {st }}$ and $2^{\text {nd }}$ generation TKIs, the mutation profile appeared almost similar whether or not MS-5 was present.

A) Ponatinib 30nM/ UT-7-315

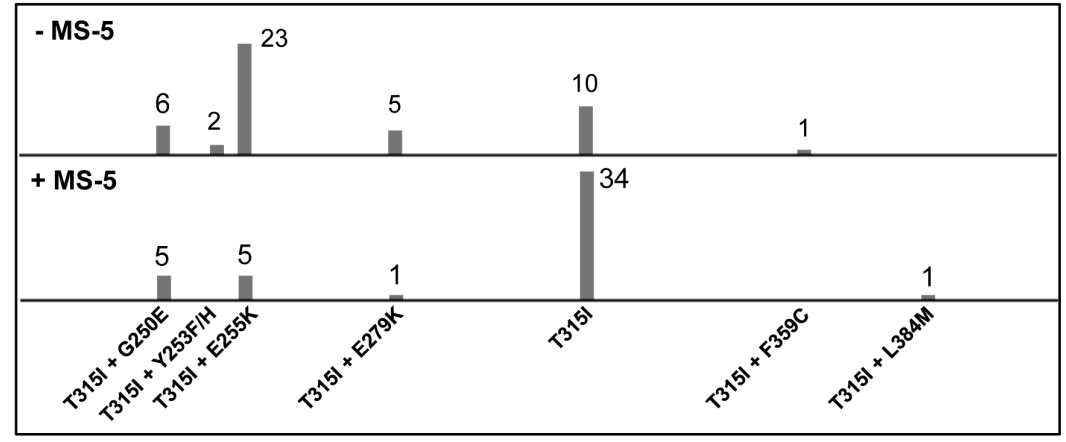

\section{B) Ponatinib 30nM/ UT-7-11}

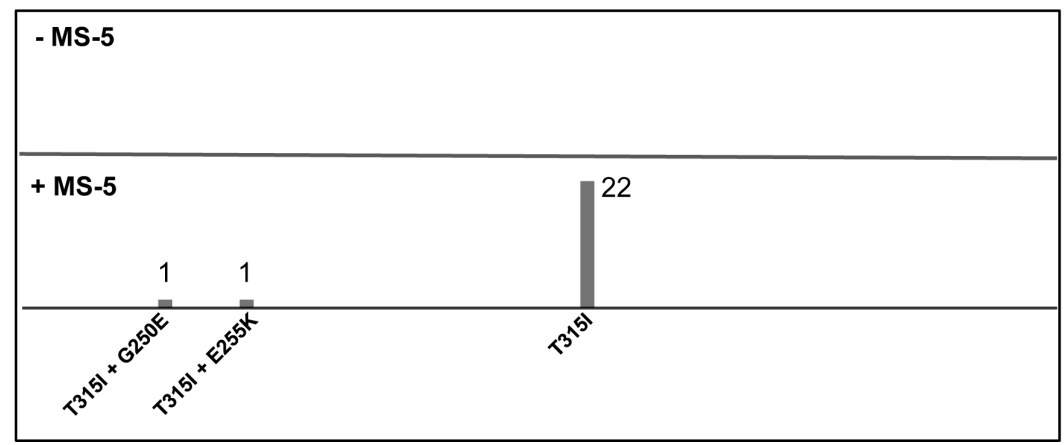

Figure 2: ENU mutagenized resistant clones from UT-7-315 or UT-7-11 cells treated with ponatinib at 30nM with or without the stromal cell line MS-5. (A) UT-7-315 clones resistant to ponatinib at a concentration of 30nM. (B) UT-7-11 clones (native $\mathrm{BCR}-\mathrm{ABL1}$ ) resistant to ponatinib at a concentration of $30 \mathrm{nM}$. Each bar represents the number of clones of the indicated KD mutation or compound mutation.
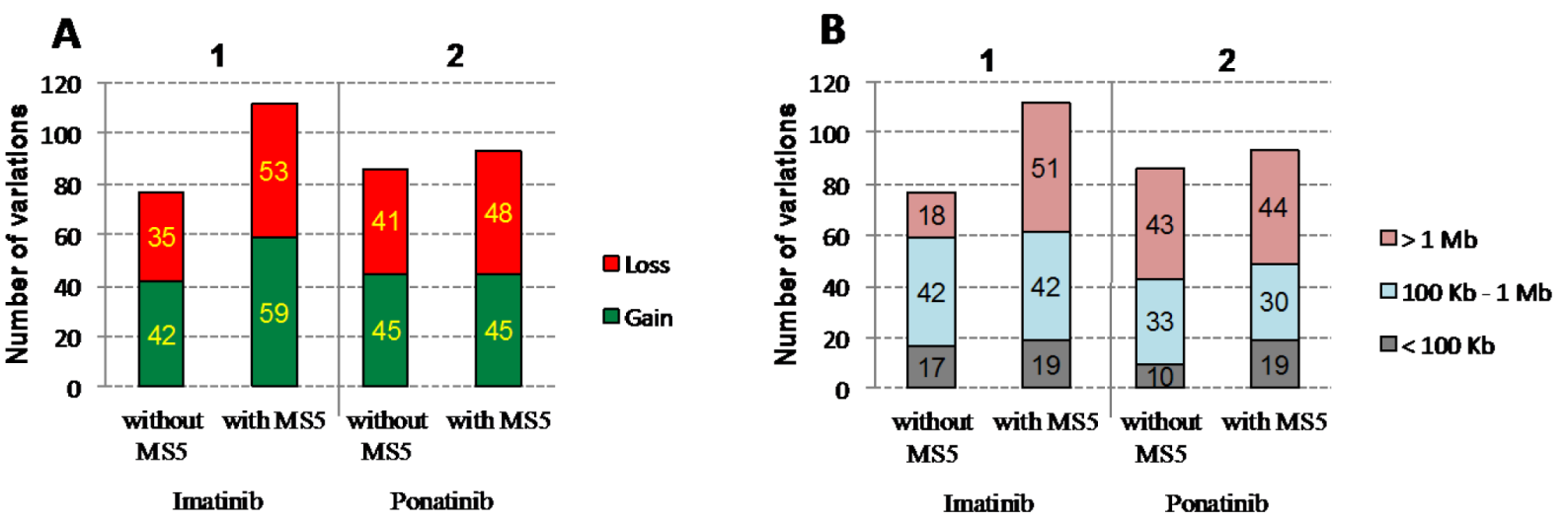

Figure 3: Array CGH analysis of mutant clones obtained from imatinib and ponatinib experiments. Potential MS-5 effects were analyzed in (1) two imatinib-resistant UT-7-11 clones harboring the E255K mutation compared with non-mutagenized UT-711 control and in (2) two ponatinib-resistant UT-7-315 clones harboring the T315I mutation alone compared with non-mutagenized UT-7315 control. The total number of variations (losses and gains) is indicated (A) along with variation size (B). 
Table 3: Genes involved in stem cell pluripotency, drug resistance, signal transduction or cancer development, recurrently amplified or deleted in the presence of MS-5.

\begin{tabular}{|c|c|c|c|c|c|c|}
\hline \multirow{3}{*}{ Gene } & \multirow{3}{*}{$\begin{array}{l}\text { Chromosome } \\
\text { location }\end{array}$} & \multicolumn{3}{|c|}{ array-CGH experiment } & \multirow{3}{*}{ Full name } & \multirow{3}{*}{ Function } \\
\hline & & imatinib & ponatinib & ponatinib & & \\
\hline & & F3 vs E5 & A23 vs C9 & A24 vs B4 & & \\
\hline $\mathrm{CD} 274$ & $9 \mathrm{p} 24.1$ & loss & loss & loss & $\begin{array}{l}\text { Programmed cell } \\
\text { death } 1 \text { ligand } 1 \\
\text { (PD-L1) }\end{array}$ & $\begin{array}{l}\text { Transmembrane protein, } \\
\text { role in immune response }\end{array}$ \\
\hline CD58 & $1 \mathrm{p} 13.1$ & loss & gain & gain & $\begin{array}{c}\text { Lymphocyte } \\
\text { function-associated } \\
\text { antigen } 3 \text { (LFA-3) }\end{array}$ & Cell molecule adhesion \\
\hline ECT2 & $3 q 26.31$ & gain & loss & loss & $\begin{array}{c}\text { Epithelial cell } \\
\text { transforming } \\
\text { sequence } 2 \text { oncogene }\end{array}$ & $\begin{array}{c}\text { Guanine nucleotide } \\
\text { exchange factor, cell } \\
\text { communication, signal } \\
\text { transduction }\end{array}$ \\
\hline TNFSF10 & $3 q 26.31$ & gain & loss & loss & $\begin{array}{c}\text { TNF-related } \\
\text { apoptosis-inducing } \\
\text { ligand (TRAIL) }\end{array}$ & $\begin{array}{l}\text { Receptor binding, cell } \\
\text { communication, signal } \\
\text { transduction }\end{array}$ \\
\hline CDKN2A & $9 \mathrm{p} 21.3$ & (1) & gain & loss & $\begin{array}{l}\text { Cyclin-dependent } \\
\text { kinase inhibitor 2A } \\
\text { (p14ARF) }\end{array}$ & $\begin{array}{c}\text { Cell cycle control } \\
\text { protein, cell } \\
\text { communication, signal } \\
\text { transduction }\end{array}$ \\
\hline CCDC6 & $10 \mathrm{q} 21.2$ & loss & (1) & loss & $\begin{array}{l}\text { Coiled coil domain } \\
\text { containing } 6\end{array}$ & $\begin{array}{l}\text { Structural constituent of } \\
\text { cytoskeleton, apoptosis }\end{array}$ \\
\hline EXT1 & $8 \mathrm{q} 24.11$ & (1) & gain & gain & $\begin{array}{c}\text { Exostosin } \\
\text { glycosyltransferase } 1\end{array}$ & Glycosyltransferase \\
\hline FOXO3 & $6 \mathrm{q} 21$ & gain & gain & (1) & $\begin{array}{c}\text { Forkhead box protein } \\
\text { O3A } \\
\end{array}$ & $\begin{array}{c}\text { Transcription factor } \\
\text { activity } \\
\end{array}$ \\
\hline JAK2 & $9 \mathrm{p} 24.1$ & loss & loss & (1) & Janus kinase 2 & $\begin{array}{c}\text { Protein-tyrosine } \\
\text { kinase activity, cell } \\
\text { communication, signal } \\
\text { transduction }\end{array}$ \\
\hline MLLT3 & $9 \mathrm{p} 21.3$ & (1) & gain & loss & $\begin{array}{c}\text { AF9, Mixed- } \\
\text { Lineage Leukemia } \\
\text { (Trithorax Homolog, } \\
\text { Drosophila) } \\
\text { Translocated To } 3 \\
\end{array}$ & $\begin{array}{l}\text { Found in acute } \\
\text { leukemias with MLL } \\
\text { rearrangement }\end{array}$ \\
\hline TMPRSS2 & $21 \mathrm{q} 22.3$ & loss & loss & (1) & $\begin{array}{l}\text { Transmembrane } \\
\text { protease serine } 2\end{array}$ & Serine protease \\
\hline $\begin{array}{r}\text { For each } \\
\text { Clones F3 }\end{array}$ & ad A 24 wer & ered & tones na & tov & $\begin{array}{l}\text { ation were compared (F3 } \\
\mathrm{E} 5, \mathrm{C} 9 \text { and } \mathrm{B} 4 \text { were reco }\end{array}$ & $\begin{array}{l}\text { E5, A23 vs C9, A24 vs B4). } \\
\text { ed from culture without MS-5 }\end{array}$ \\
\hline
\end{tabular}

A majority of clones harbored p-loop mutations (G250E, Q252H, Y253H, E255K) or the T315I substitution (Fig. 1). Some other mutations (E275K, E279K, E281K, H396R) were rarely detected. In the nilotinib assay, clones from methylcellulose culture (with MS-5) appeared somewhat enriched in T315I (Fig. 1B). Concerning dasatinib selection, a predominance of the gatekeeper mutation was observed with or without MS-5 feeder (Fig. 1C). Mutation profiles with UT-7-315 and ponatinib selection displayed interesting data. As expected, all resistant clones carried the T315I substitution. In many cases, in addition to the gatekeeper mutation, direct sequencing detected BCRABL1 KD mutations located within the p-loop (G250E, Y253F/H, E255K) or elsewhere (E279K, F359C, L384M). When UT-7-315 cells were cultured in the absence of MS-5, clones with compound mutation (T315I + another mutation) represented the majority of resistant clones (Fig. 2A). Conversely, in the presence of MS-5 cells, resistant clones mainly harbored the T315I mutation alone. Consequently, the mutation profiles appeared 
different according to MS-5 condition. Finally, resistant UT-7-11 cells selected by ponatinib in MS-5 cocultures carried the gatekeeper substitution alone in most cases, whereas no outgrowth was observed without MS-5 (Fig. 2B). Compound mutations were found in only two clones (T315I/G250E, T315I/E255K).

\section{Array-comparative genomic hybridization experiments}

To examine the role of the MS-5 niche, we first analyzed by array-CGH (1) two imatinib-resistant UT-711 clones harboring the $\mathrm{E} 255 \mathrm{~K}$ mutation compared with UT-7-11 control that did not undergo ENU mutagenesis, and (2) two ponatinib-resistant UT-7-315 clones with the T315I mutation alone compared with non-mutagenized UT-7-315 control (Fig. 3). In each condition, one clone was isolated and amplified in the absence of MS-5 stromal cells and the other in the presence of MS-5. Figure 3A reveals the total copy number variations (CNVs) in clones cultured in the presence of MS-5 feeder as compared to clones obtained without MS-5 (112 vs 77 for imatinib screening, 93 vs 86 for ponatinib screening). In these experiments, size variations are comparable, except for imatinib condition, in which an increase in deletions/ insertions $>1 \mathrm{Mb}$ was observed with MS-5 (Fig. 3B).

Secondly, direct array-CGH experiments were performed using the culture in the absence of MS-5 as a control, in order to detect potential niche-induced abnormalities. For that purpose, two imatinib-resistant clones harboring $\mathrm{E} 255 \mathrm{~K}$ and four ponatinib-resistant clones with the E255K/T315I compound mutation (analyzed pairwise) were compared in 3 independent experiments (Supplementary Table S2). A larger number of CNVs were seen in imatinib experiments as compared to ponatinib screening. Interestingly, results from the two independent ponatinib comparisons appeared quite similar. The details of the 3 array-CGH experiments are shown in Supplementary Tables S3-S5. Data pooling allowed us to more precisely examine the recurrent variations (Supplementary Table S6). Generally, five chromosomal loci were identified (1p13.1, 1q42.2, 3q26.31, 9p24.1 and Yq11.223) harboring losses or gains (Supplementary Fig. S4). Using filtering for genes involved in stem cell pluripotency, drug resistance, signal transduction and cancer, a few genes recurrently affected by genomic variations were identified, including TNFSF10 and FOXO3 (Table 3).

\section{DISCUSSION}

Use of TKIs has modified the therapeutic landscape of CML, with a major beneficial effect on overall and disease-free survival. However, a minority of patients develop a resistance to imatinib or $2^{\text {nd }}$ generation TKIs, due in part to BCR-ABL1 kinase domain mutations [17]. This resistance could also be oncogene-independent and mediated by the microenvironment. Recently, several reports have highlighted the involvement of the hematopoietic niche in the leukemogenesis process, leading to new concepts such as "leukemic niche" [18]. In the present work, we used a niche-based cell mutagenesis assay to investigate the role of the hematopoietic niche in resistance towards four drugs used in CML (imatinib, nilotinib, dasatinib and ponatinib). The usefulness of this type of experiment has been demonstrated, in particular for the characterization of TKI resistance profile in CML $[11,19]$. Moreover, ENU has been shown to be a potent mutagenic agent since it is able to induce point mutations at a rate $\sim 100$-fold higher than the rate of spontaneous mutations [20]. In our assay, we used the MS-5 murine mesenchymal stromal cell line, which is known to produce a surrogate hematopoietic niche supporting human hematopoiesis [21]. In addition to this supportive capacity, MS-5 was recently shown to promote vasculogenesis and angiogenesis, two other important processes regulated in and by the niche [22].

In the assay relative to $1^{\text {st }}$ and $2^{\text {nd }}$ generation TKIs, we found that the percentage of UT-7-11 resistant clones decreased from imatinib (more than 50\%) to dasatinib (approximately 10\%) whatever the MS-5 condition. This percentage appeared intermediate (30\%) with nilotinib in the absence of MS-5 feeder. Overall, these results seem to be in accordance with the increasing efficacy of $2^{\text {nd }}$ generation TKIs as reported in the literature [23]. Concerning nilotinib in MS-5 presence, no positive wells were detected. Subsequent microscopic examinations displayed viable cells lodged in the MS-5 niche. However, after replating 24 "negative" wells in methylcellulose, hematopoietic colonies were clearly observed in all cases. With the exception of the latter case, MS-5 stromal niche did not seem to influence resistance towards $1^{\text {st }}$ and $2^{\text {nd }}$ generation TKIs. A BCR-ABL1 KD mutation was characterized in most of the resistant clones recovered from imatinib and dasatinib experiments, and only in half of the cases with nilotinib, regardless of the presence of MS-5 stromal niche. Imatinib/dasatinib mutation profiles did not reveal a significant effect of the MS-5 feeder, but they remained consistent with previous ENU-based mutagenesis studies [19]. P-loop mutations (G250E, Y253H, E255K) and the T315I substitution were detected essentially in the imatinib and dasatinib assays respectively. As previously reported, the nilotinib mutation profile appeared intermediate [24]. In this case, it is uncertain whether or not the MS-5 feeder effects selection of T315I mutants.

Concerning ponatinib assays on UT-7-315 cell line, a sizable increase in the percentage of resistant clones was observed in the presence of MS-5 stromal cells (two independent experiments). When combined with the results of the experiment on UT-7-11 (non-T315I) 
cells, these data could suggest both the critical role of the surrogate niche, and an environment-mediated resistance phenomenon. Another exciting result was the presence of a majority (78\%) of compound mutations (T315I + other mutation) in the absence of MS-5, and the detection of the T315I mutation alone in most of the resistant clones $(87.5 \%)$ recovered from MS-5 condition. According to these results, we can formulate two hypotheses for T315Iresistance to ponatinib. First, in the absence of the stromal niche, a compound mutation (T315I + another mutation) could be necessary to induce a complete resistance. Indeed, cell-based screenings have demonstrated that ponatinib was potent on single point mutations but less effective on several compound mutations [11]. Second, in the presence of the MS-5 microenvironment, UT-7 cells harboring the T315I mutation alone could survive ponatinib. In this model, T315I mutation and stromal niche could jointly play a crucial role in the acquisition of ponatinib resistance.

T315I substitution is the most frequent BCR-ABL1 $\mathrm{KD}$ mutation and leads to complete resistance to $1^{\text {st }}$ and $2^{\text {nd }}$ generation TKIs $[17,25]$. These T315I mutants appeared to be clearly different from non-mutated BCR-ABL1 leukemic cells. Indeed, T315I mutants have been shown to display an increased oncogenic capability despite reduced tyrosine kinase activity, thereby suggesting altered substrate recognition [26]. The gatekeeper mutation has also been associated with severe transformation potency in the absence of fetal bovine serum or growth factors [27]. In addition, it has been suggested that T315I mutation may confer additional leukemogenic activity to nonmutated BCR-ABL1 related to the phosphorylation of endogenous BCR [28]. All of these features could give rise to T315I "specific signaling pathways", highlighting the gatekeeper substitution as the most particular BCRABL1 KD mutation. These gain-of-function properties could therefore be associated with extrinsic mechanisms of resistance. However, ponatinib has been shown to be active against BCR-ABL1 mutants (in particular the T315I mutant) in vitro as well as in vivo [11,29]. Altered BCR-ABL1 signaling potentially due to the T315I mutation, associated with a stroma-mediated influence on these particular signaling pathways, could represent an explanation for ponatinib escape. Based on IC50 values, it is noticeable that T315I show an intermediate resistance to ponatinib [30]. Moreover, it has recently been reported that TKI IC50 values were substantially increased in the presence of human stromal cell conditioned media [31]. Overall, these data suggest that T315I mutants, supported by a stromal niche, could survive ponatinib through interactions mediated by direct contact or soluble factors.

Regarding the potential support to TKI resistance provided by MS-5 stromal cells, we wondered whether these cells could promote genomic instability. It has already been reported that this phenomenon could be induced by tumoral microenvironment, resulting in genomic events influencing drug resistance [32]. Critical components regulated by the niche as hypoxia or metalloproteinases have been shown to play a sizable role in genomic instability and in the production of reactive oxygen species $[33,34]$. In the present study, array-CGH experiments suggest a slight involvement of MS-5 niche in the number of genetic modifications. Among the recurring abnormalities, the gain of genomic regions including the $\mathrm{FOXO3}$ gene can be of interest. This transcription factor was reported to be crucial to the maintenance of leukemic cells in CML via TGF- $\beta$ signaling [35]. The TNFSF 10 (TRAIL) gene, located in the $3 \mathrm{q} 26.31$ region gained in imatinib or lost in ponatinib experiments, has been shown to sensitize imatinib-resistant cells to apoptosis by down-regulating $c-F L I P$. This latter gene is implicated in oncogene-independent resistance on account of the fact that leukemic cells exhibit attenuated BCR-ABL1 activity [36]. Since it has been suggested that the hematopoietic niche could induce a TRAIL-mediated apoptosis, investigation of this pathway in the context of CML resistance (especially with ponatinib) could be of importance $[37,38]$. Finally, the $C D K N 2 A / B$ locus appears to be involved in the progression of CML, and JAK2 could play a role in TKI resistance through a BCR-ABL1/JAK2 network $[39,40]$.

Nowadays, in clinical practice, the influence of BCR-ABL1 KD mutations in TKI resistance is decreasing. Causes of mutation-independent resistance, particularly the role of the hematopoietic niche, are currently under investigation. Primitive HSCs are refractory to all of the TKIs used in clinical practice [12-14]. This resistance can be due not only to the persistence of quiescent leukemic cells, but also to molecular mechanisms of resistance related to the bone marrow microenvironment $[41,42]$. The hematopoietic niche could then appear as a critical target to cure CML [43]. Stroma-mediated protection from TKI treatment has in fact been reported in several works, all of which highlight the critical role of the hematopoietic niche in TKI resistance $[44,45]$.

In conclusion, we have reported a niche-based cell mutagenesis assay performed on human UT-7 cells that allowed for screening of TKI-resistant BCRABL1-expressing clones. For the first time, we have described stromal-mediated ponatinib resistance for BCR-ABL $1^{\mathrm{T} 315 \mathrm{I}}$ mutants. In the absence of MS-5 niche, compound mutations appeared to be the major way to escape ponatinib therapy, especially via the occurrence of p-loop mutations in addition to T315I. In the presence of the niche, resistance appeared due to the close association of T315I mutants and stromal cells, suggesting a crosstalk between the two components. Overall, we conclude that stromal niche could play a crucial role in conferring resistance to ponatinib, by providing survival signals and favoring genetic instability, which is likely to lead to the occurrence of novel mutations. 


\section{MATERIALS AND METHODS}

\section{Cell lines}

In the present assay, the murine stromal cell line MS-5 was used as a niche model. UT-7 cell line, established from a patient with acute megakaryoblastic leukemia, was used as a model of leukemic cells [46]. UT-7-11 cells were generated by transduction of native BCR-ABL1 gene as previously described [47]. UT-7 cells harboring the T315I BCR-ABL1 (UT-7-315) were generated by lipofectamine transfection of a MIGR-BCRABL1-T315I plasmid.

\section{Drugs and reagents}

TKIs (imatinib, nilotinib, dasatinib and ponatinib) used in this study were purchased from Selleck Chemicals (Houston, Texas) and stored at $-20{ }^{\circ} \mathrm{C}$ as $1 \mathrm{mM}$ stock solutions in DMSO. Before experiments, fresh dilutions were prepared with culture medium. ENU (Sigma Aldrich, St. Louis, Missouri) was reconstituted with DMSO as 50 $\mathrm{mg} / \mathrm{ml}$ stock solution, aliquoted and stored at $-80^{\circ} \mathrm{C}$.

\section{In Vitro-ENU Mutagenesis}

UT-7-11 or UT-7-315 were cultured in complete MEM alpha medium (Life Technologies, Carlsbad, California) containing 10\% FBS, L-glutamine (Life Technologies) and $1 \%$ penicillin/streptomycin (Life Technologies). ENU was added to UT-7 cells at a concentration of $50 \mu \mathrm{g} / \mathrm{ml}$, followed by a $24 \mathrm{~h}$ culture. This dose was minimally toxic to our cells ( $20 \%$ cell death). Cells were then washed three times with culture medium, replated in complete medium and expanded over one week.

\section{Resistance screening and mutant cell expansion}

ENU exposed UT-7 cells were cultured in 96-well plates at $10^{5}$ cells/well in $200 \mu 1$ medium in the presence or in the absence of MS-5 and in the presence of either imatinib $(2 \mu \mathrm{M})$, nilotinib $(75 \mathrm{nM})$, dasatinib $(10 \mathrm{nM})$ or ponatinib $(30 \mathrm{nM})$. MS-5 cells were plated a day before in 96-well plates at a concentration of 6000 cells/well. Wells were monitored for cell growth by microscopic inspection twice a week for 5-6 weeks. 24 positive wells, randomly picked, were then transferred to 24-well plates and expanded using the same concentration of TKI (Supplementary Fig. S1).

\section{Detection of BCR-ABL1 KD mutations}

After expansion, TKI-resistant cells were lyzed in Trizol solution (Trizol reagent, Life Technologies). Total RNA was extracted using manufacturer's protocol, and cDNA was prepared from $2 \mu \mathrm{g}$ of total RNA using the High-Capacity cDNA Reverse transcription kit (Life Technologies). The BCR-ABL1 tyrosine kinase domain (corresponding to amino acids 242 to 427 ) was amplified by two overlapping PCR reactions and DGGE experiments were performed as previously described [48]. For direct sequencing, PCR products were purified (Illustra Exostar 1-step, VWR, Radnor, Pennsylvania) and sequenced using the BigDye Terminator v3.1 Cycle sequencing kit on an ABI 3500Dx (Life Technologies). Mutation analysis was carried out using the Mutation Surveyor software (SoftGenetics, State College, PA).

\section{Oligonucleotide array-comparative genomic hybridization (array-CGH)}

Array-CGH was conducted on UT-7-11 and UT-7315 mutant clones selected from imatinib and ponatinib screenings respectively. As a control, we used UT-7 cell lines that did not undergo ENU mutagenesis. Genomic DNA was isolated using DNeasy Blood and Tissu Kit (Qiagen, Courtaboeuf, France). DNA concentrations were estimated using a NanoDrop ND-1000 spectrophotometer (NanoDrop Technologies, Wilmington, DE). The genomic imbalances were analyzed using the human CGH 12x135K Whole-Genome Tiling v3.0 Array (Roche NimbleGen, Meylan, France). All array hybridizations were performed according to the manufacturer's recommended protocols. Briefly, $0.5 \mu \mathrm{g}$ of genomic DNA were fluorescently labeled with the Roche NimbleGen Dual-Color DNA labeling kit (Roche NimbleGen). Male human genomic DNA (Promega, Charbonnière, France) was used as reference. Cy5-dUTP cell line DNA and gender-matched reference DNA labeled with Cy3-dUTP were denatured prior to hybridization (NimbleGen Hybridization kit) for $48 \mathrm{~h}$ at $42^{\circ} \mathrm{C}$ in the Hybridization System 4 (Roche NimbleGen). After washing (NimbleGen Wash Buffer Kit), the slides were scanned on a Roche NimbleGen MS200 Microarray Scanner. Captured images were processed with NimbleScan software and data analysis was performed with DEVA software v1.0.2 (Roche Nimblegen). The Nexus Copy Number Standard edition software (Proteigene, Saint-Marcel, France) algorithm was used for statistical analysis according to the version 18 of the Human genome built (http://genome.ucsc.edu/). Copy number variations $(\mathrm{CNV})$ were considered significant if they were defined by 5 or more oligonucleotides spanning at least $50 \mathrm{~Kb}$. 


\section{ACKNOWLEDGEMENTS}

The authors would like to thank Professor Michael W. Deininger (Huntsman Cancer Institute, University of Utah, Salt Lake City) for providing the MIGR-BCRABL1-T315I plasmid. The authors also wish to thank Jeffrey Arsham, an American medical translator, for editing our original English-language manuscript. Djamel Aggoune (PhD student) was funded by by grants from the foundations "Sport et Collection", Totary Club de Civray" and NRB-Vaincre le Cancer (Villejuif)

\section{Conflict of interest}

A.G. Turhan has received lecture fees from Bristol Myers Squibb, and research funding from Novartis Oncology and Bristol Myers Squibb. The remaining authors declare no competing financial interests.

\section{REFERENCES}

1. Goldman JM, Melo JV. Chronic myeloid leukemia-advances in biology and new approaches to treatment. N Engl J Med 2003;349:1451-64.

2. Skorski T. BCR/ABL regulates response to DNA damage: the role in resistance to genotoxic treatment and in genomic instability. Oncogene 2002;21:8591-604.

3. Maru Y. Molecular biology of chronic myeloid leukemia. Cancer Sci 2012;103:1601-10.

4. Druker BJ, Tamura S, Buchdunger E, Ohno S, Segal GM, Fanning S, Zimmermann J, Lydon NB. Effects of a selective inhibitor of the Abl tyrosine kinase on the growth of Bcr-Abl positive cells. Nat Med 1996;2:561-6.

5. Hochhaus A, O'Brien SG, Guilhot F, Druker BJ, Branford S, Foroni L, Goldman JM, Muller MC, Radich JP, Rudoltz M, Mone M, Gathmann I, Hughes TP, et al. Six-year follow-up of patients receiving imatinib for the firstline treatment of chronic myeloid leukemia. Leukemia 2009;23:1054-61.

6. Apperley JF. Part I: mechanisms of resistance to imatinib in chronic myeloid leukaemia. Lancet Oncol 2007;8:1018-29.

7. Ernst T, Hoffmann J, Erben P, Hanfstein B, Leitner A, Hehlmann R, Hochhaus A, Muller MC. ABL single nucleotide polymorphisms may masquerade as BCR-ABL mutations associated with resistance to tyrosine kinase inhibitors in patients with chronic myeloid leukemia. Haematologica 2008;93:1389-93.

8. Weisberg E, Manley PW, Breitenstein W, Bruggen J, Cowan-Jacob SW, Ray A, Huntly B, Fabbro D, Fendrich G, Hall-Meyers E, Kung AL, Mestan J, Daley GQ, et al. Characterization of AMN107, a selective inhibitor of native and mutant Bcr-Abl. Cancer Cell 2005;7:129-41.

9. Shah NP, Tran C, Lee FY, Chen P, Norris D, Sawyers CL. Overriding imatinib resistance with a novel ABL kinase inhibitor. Science 2004;305:399-401.

10. O'Hare T, Walters DK, Stoffregen EP, Jia T, Manley PW, Mestan J, Cowan-Jacob SW, Lee FY, Heinrich MC, Deininger MW, Druker BJ. In vitro activity of Bcr-Abl inhibitors AMN107 and BMS-354825 against clinically relevant imatinib-resistant Abl kinase domain mutants. Cancer Res 2005;65:4500-5.

11. O'Hare T, Shakespeare WC, Zhu X, Eide CA, Rivera VM, Wang F, Adrian LT, Zhou T, Huang WS, Xu Q, Metcalf CAr, Tyner JW, Loriaux MM, et al. AP24534, a pan-BCRABL inhibitor for chronic myeloid leukemia, potently inhibits the T315I mutant and overcomes mutation-based resistance. Cancer Cell 2009;16:401-12.

12. Graham SM, Jorgensen HG, Allan E, Pearson C, Alcorn MJ, Richmond L, Holyoake TL. Primitive, quiescent, Philadelphia-positive stem cells from patients with chronic myeloid leukemia are insensitive to STI571 in vitro. Blood 2002;99:319-25.

13. Copland M, Hamilton A, Elrick LJ, Baird JW, Allan EK, Jordanides N, Barow M, Mountford JC, Holyoake TL. Dasatinib (BMS-354825) targets an earlier progenitor population than imatinib in primary CML but does not eliminate the quiescent fraction. Blood 2006;107:4532-9.

14. Jorgensen HG, Allan EK, Jordanides NE, Mountford JC, Holyoake TL. Nilotinib exerts equipotent antiproliferative effects to imatinib and does not induce apoptosis in CD34+ CML cells. Blood 2007;109:4016-9.

15. Nair RR, Tolentino J, Hazlehurst LA. The bone marrow microenvironment as a sanctuary for minimal residual disease in CML. Biochem Pharmacol 2010;80:602-12.

16. Chomel JC, Turhan AG. Chronic myeloid leukemia stem cells in the era of targeted therapies: resistance, persistence and long-term dormancy. Oncotarget 2011;2:713-27.

17. Baccarani $\mathrm{M}$, Deininger MW, Rosti $\mathrm{G}$, Hochhaus A, Soverini S, Apperley JF, Cervantes F, Clark RE, Cortes JE, Guilhot F, Hjorth-Hansen H, Hughes TP, Kantarjian $\mathrm{HM}$, et al. European LeukemiaNet recommendations for the management of chronic myeloid leukemia. Blood 2013;122:872-84.

18. Schepers K, Pietras EM, Reynaud D, Flach J, Binnewies M, Garg T, Wagers AJ, Hsiao EC, Passegue E. Myeloproliferative neoplasia remodels the endosteal bone marrow niche into a self-reinforcing leukemic niche. Cell Stem Cell 2013;13:285-99.

19. Bradeen HA, Eide CA, O'Hare T, Johnson KJ, Willis SG, Lee FY, Druker BJ, Deininger MW. Comparison of imatinib mesylate, dasatinib (BMS-354825), and nilotinib (AMN107) in an N-ethyl-N-nitrosourea (ENU)-based mutagenesis screen: high efficacy of drug combinations. Blood 2006;108:2332-8.

20. Feng J, Wang H, Morse HCr. Functional deficiency in IL-7 caused by an N-ethyl-N-nitrosourea-induced point mutation. Genetics 2007;175:545-51.

21. Itoh $\mathrm{K}$, Tezuka $\mathrm{H}$, Sakoda $\mathrm{H}$, Konno $\mathrm{M}$, Nagata $\mathrm{K}$, 
Uchiyama T, Uchino H, Mori KJ. Reproducible establishment of hemopoietic supportive stromal cell lines from murine bone marrow. Exp Hematol 1989;17:145-53.

22. Zhou B, Tsaknakis G, Coldwell KE, Khoo CP, Roubelakis MG, Chang CH, Pepperell E, Watt SM. A novel function for the haemopoietic supportive murine bone marrow MS-5 mesenchymal stromal cell line in promoting human vasculogenesis and angiogenesis. Br J Haematol 2012;157:299-311.

23. Mealing S, Barcena L, Hawkins N, Clark J, Eaton V, Hirji I, Davis C. The relative efficacy of imatinib, dasatinib and nilotinib for newly diagnosed chronic myeloid leukemia: a systematic review and network meta-analysis. Exp Hematol Oncol 2013;2:5.

24. von Bubnoff N, Manley PW, Mestan J, Sanger J, Peschel C, Duyster J. Bcr-Abl resistance screening predicts a limited spectrum of point mutations to be associated with clinical resistance to the Abl kinase inhibitor nilotinib (AMN107). Blood 2006;108:1328-33.

25. Gorre ME, Mohammed M, Ellwood K, Hsu N, Paquette R, Rao PN, Sawyers CL. Clinical resistance to STI-571 cancer therapy caused by BCR-ABL gene mutation or amplification. Science 2001;293:876-80.

26. Skaggs BJ, Gorre ME, Ryvkin A, Burgess MR, Xie Y, Han Y, Komisopoulou E, Brown LM, Loo JA, Landaw EM, Sawyers CL, Graeber TG. Phosphorylation of the ATPbinding loop directs oncogenicity of drug-resistant BCRABL mutants. Proc Natl Acad Sci U S A 2006;103:1946671.

27. Griswold IJ, MacPartlin M, Bumm T, Goss VL, O'Hare T, Lee KA, Corbin AS, Stoffregen EP, Smith C, Johnson K, Moseson EM, Wood LJ, Polakiewicz RD, et al. Kinase domain mutants of Bcr-Abl exhibit altered transformation potency, kinase activity, and substrate utilization, irrespective of sensitivity to imatinib. Mol Cell Biol 2006;26:6082-93.

28. Mian AA, Schull M, Zhao Z, Oancea C, Hundertmark A, Beissert T, Ottmann OG, Ruthardt M. The gatekeeper mutation T315I confers resistance against small molecules by increasing or restoring the ABL-kinase activity accompanied by aberrant transphosphorylation of endogenous BCR, even in loss-of-function mutants of BCR/ ABL. Leukemia 2009;23:1614-21.

29. Cassuto O, Dufies M, Jacquel A, Robert G, Ginet C, Dubois A, Hamouda A, Puissant A, Luciano F, Karsenti JM, Legros L, Cassuto JP, Lenain P, et al. All tyrosine kinase inhibitorresistant chronic myelogenous cells are highly sensitive to ponatinib. Oncotarget 2012;3:1557-65.

30. Redaelli S, Mologni L, Rostagno R, Piazza R, Magistroni V, Ceccon M, Viltadi M, Flynn D, Gambacorti-Passerini C. Three novel patient-derived BCR/ABL mutants show different sensitivity to second and third generation tyrosine kinase inhibitors. Am J Hematol 2012;87:E125-8.

31. Quintarelli C, De Angelis B, Errichiello S, Caruso S, Esposito N, Colavita I, Raia M, Pagliuca S, Pugliese
N, Risitano AM, Picardi M, Luciano L, Saglio G, et al. Selective strong synergism of Ruxolitinib and second generation tyrosine kinase inhibitors to overcome bone marrow stroma related drug resistance in chronic myelogenous leukemia. Leuk Res 2013

32. Raaijmakers MH. Niche contributions to oncogenesis: emerging concepts and implications for the hematopoietic system. Haematologica 2011;96:1041-8.

33. Bristow RG, Hill RP. Hypoxia and metabolism. Hypoxia, DNA repair and genetic instability. Nat Rev Cancer 2008;8:180-92.

34. Radisky DC, Przybylo JA. Matrix metalloproteinaseinduced fibrosis and malignancy in breast and lung. Proc Am Thorac Soc 2008;5:316-22.

35. Naka K, Hoshii T, Muraguchi T, Tadokoro Y, Ooshio T, Kondo Y, Nakao S, Motoyama N, Hirao A. TGF-betaFOXO signalling maintains leukaemia-initiating cells in chronic myeloid leukaemia. Nature 2010;463:676-80.

36. Park SJ, Kim MJ, Kim HB, Kang CD, Kim SH. Sensitization of imatinib-resistant CML cells to TRAILinduced apoptosis is mediated through down-regulation of Bcr-Abl as well as c-FLIP. Biochem J 2009;420:73-81.

37. Mace TA, Yamane N, Cheng J, Hylander BL, Repasky EA. The potential of the tumor microenvironment to influence Apo2L/TRAIL induced apoptosis. Immunol Invest 2006;35:279-96.

38. Perez LE, Parquet N, Shain K, Nimmanapalli R, Alsina M, Anasetti C, Dalton W. Bone marrow stroma confers resistance to Apo2 ligand/TRAIL in multiple myeloma in part by regulating c-FLIP. J Immunol 2008;180:1545-55.

39. Samanta AK, Chakraborty SN, Wang Y, Schlette E, Reddy EP, Arlinghaus RB. Destabilization of Bcr-Abl/ Jak2 Network by a Jak2/Abl Kinase Inhibitor ON044580 Overcomes Drug Resistance in Blast Crisis Chronic Myelogenous Leukemia (CML). Genes Cancer 2010;1:34659.

40. Williams RT, Sherr CJ. The INK4-ARF (CDKN2A/B) locus in hematopoiesis and BCR-ABL-induced leukemias. Cold Spring Harb Symp Quant Biol 2008;73:461-7.

41. Bewry NN, Nair RR, Emmons MF, Boulware D, Pinilla-Ibarz J, Hazlehurst LA. Stat3 contributes to resistance toward BCR-ABL inhibitors in a bone marrow microenvironment model of drug resistance. Mol Cancer Ther 2008;7:3169-75.

42. Yamamoto-Sugitani M, Kuroda J, Ashihara E, Nagoshi H, Kobayashi T, Matsumoto Y, Sasaki N, Shimura Y, Kiyota M, Nakayama R, Akaji K, Taki T, Uoshima N, et al. Galectin-3 (Gal-3) induced by leukemia microenvironment promotes drug resistance and bone marrow lodgment in chronic myelogenous leukemia. Proc Natl Acad Sci U S A 2011;108:17468-73.

43. Schmidt T, Kharabi Masouleh B, Loges S, Cauwenberghs S, Fraisl P, Maes C, Jonckx B, De Keersmaecker K, Kleppe M, Tjwa M, Schenk T, Vinckier S, Fragoso R, et al. Loss 
or inhibition of stromal-derived PlGF prolongs survival of mice with imatinib-resistant Bcr-Abl1(+) leukemia. Cancer Cell 2011;19:740-53.

44. Weisberg E, Wright RD, McMillin DW, Mitsiades C, Ray A, Barrett R, Adamia S, Stone R, Galinsky I, Kung AL, Griffin JD. Stromal-mediated protection of tyrosine kinase inhibitor-treated BCR-ABL-expressing leukemia cells. Mol Cancer Ther 2008;7:1121-9.

45. Vianello F, Villanova F, Tisato V, Lymperi S, Ho KK, Gomes AR, Marin D, Bonnet D, Apperley J, Lam EW, Dazzi F. Bone marrow mesenchymal stromal cells nonselectively protect chronic myeloid leukemia cells from imatinib-induced apoptosis via the CXCR4/CXCL12 axis. Haematologica 2010;95:1081-9.

46. Komatsu N, Nakauchi H, Miwa A, Ishihara T, Eguchi M, Moroi M, Okada M, Sato Y, Wada H, Yawata Y, et a. Establishment and characterization of a human leukemic cell line with megakaryocytic features: dependency on granulocyte-macrophage colony-stimulating factor, interleukin 3, or erythropoietin for growth and survival. Cancer Res 1991;51:341-8.

47. Issaad $\mathrm{C}$, Ahmed $\mathrm{M}$, Novault $\mathrm{S}$, Bonnet ML, Bennardo T, Varet B, Vainchenker W, Turhan AG. Biological effects induced by variable levels of BCR-ABL protein in the pluripotent hematopoietic cell line UT-7. Leukemia 2000;14:662-70.

48. Sorel N, Chazelas F, Brizard A, Chomel JC. Doublegradient-denaturing-gradient gel electrophoresis for mutation screening of the BCR-ABL tyrosine kinase domain in chronic myeloid leukemia patients. Clin Chem 2005;51:1263-6. 